\title{
Zymogram Analysis of Alkaline Keratinase Produced by Nitrogen Fixing Bacillus pumilus ZED17 Exhibiting Multiprotease Enzyme Activities
}

\author{
Marzieh Talebi ${ }^{1}$, Giti Emtiazi ${ }^{2,}$, Abbas Akhavan Sepahy $^{3}$, Saeideh Zaghian ${ }^{2}$ \\ ${ }^{1}$ Department of Biology, Science and Research Branch of Islamic Azad University, Tehran, IR Iran \\ ${ }_{3}^{2}$ Department of Biology, Faculty of Sciences, University of Isfahan, Isfahan, IR Iran \\ 3 Department of Microbiology, North Tehran Branch of Islamic Azad University, Tehran, IR Iran \\ ${ }^{*}$ Corresponding author: Giti Emtiazi, Department of Biology, Faculty of Sciences, University of Isfahan, P.O. Box 117-81744, Isfahan, IR Iran. Tel: +98-3117932457, Fax: +98-3117932456, \\ E-mail:emtiazi@yahoo.com.
}

Received: August 30, 2012; Revised: January 22, 2013; Accepted: February 18, 2013

\begin{abstract}
Background: One group of significant enzymes produced by Bacillus genus are alkaline proteases with several important applications in the daily life as well as common industries such as food, detergents, leather, alcohol and beer production and medical and sanitary industries, beside wastewater treatment, , biotransformation, hydrolyzed proteins and oil manufacturing.

Objectives: In this paper, keratinase activity and zymogram analysis of Bacillus pumilus ZED17 using different conditions and substrates are reported.

Materials and Methods: The nitrogen fixing Bacillus, obtained from heated see water, was enriched on feather as the only sources of carbon, nitrogen and energy. It was also determined whether the isolated nitrogen fixing Bacillus exhibited extracellular proteolytic activity on feather, meat, gelatin and casein. Biochemical tests, carbohydrate fermentation patterns and 16srRNA detection were employed for identification of the isolated strain. Furthermore, the extracellular proteolytic activity using different protein substrates was investigated. Results: B. pumilus ZED17 is one of the best strains enriched on feather, of which the extracellular proteolytic activities are exhibited. Activity-pH profiles were resoluted in buffers with different $\mathrm{pH}$ levels. Extracellular enzyme activities were assayed using different proteins and feathers. Keratinase activity was observed at neutral and alkaline, but not low pH levels. This enzyme demonstrated to have multiactivity. zymogram test revealed a 50-kD Caseinase produced by this strain. The optimum keratinase activity was at $\mathrm{pH} 8.0$ and $40^{\circ} \mathrm{C}$, using keratin as a substrate.

Conclusions: Since the isolated strain is halotolerant and nitrogen fixing, it is a good candidate for alkaline protease production, and soil fertilizing, in addition to biofertilizer production out of poultry and fish byproduct.
\end{abstract}

Keywords: Bacillus pumilus; Keratinase; Feathers

\section{Background}

Among all microorganisms, spore-forming Bacillus strains are found in various natural areas, are resistant to various environments and ecosystem, easy to isolate, have different physiological abilities and produce valuable biological products. Due to their endospores, they are resistance to UV, heat, $\mathrm{pH}$ and their hydrolysis activity can be used in different industries (1-3). Bacillus sp. is gram positive, endospore forming and straight rods developing that forms individual endospore in each cell against extreme conditions. In these bacteria, presence of oxygen cannot prevent the sporulation phase.

One group of significant biological substances that are produced by the genus Bacillus are alkaline proteases with several important applications in the daily life and common industries such as food detergent, alcohol and beer production medical and cosmetic/sanitary and leather, beside wastewater treatment, biotransformation, hydrolyzed proteins, oil manufacturing (2-4). Bacillus sp. produces tremendous hydrolysing enzymes out of waste materials. Among all these enzymes, alkaline protease is a very important product which several industries have been involved in its production and marketing all around the world $(1,3,4)$. Bacillus sp. is detected and isolated using $80^{\circ} \mathrm{C}$ water bath which kills all the vegetative bacteria and resistant forms except Bacilli and Clostridia endospores.

An alkaline protease has been produced by Bacillus cereus MCM B-326, using a medium containing soya flour, starch and wheat bran as the main components. The produced enzyme has been applied for the dehairing of buffalo hide (5). Several agro-industrial waste substances have been used to produce alkaline protease from an alkalophilic Bacillus sp., among which the green gram husk 
resulted in the highest production of the enzyme, using solid-state fermentation (6). Feather is resistant to protease hydrolysis due to the existence of different bonds in its structure but some microorganisms are capable of its hydrolysis $(7,8)$. Although keratin is a poultry byproduct, it can be transformed to an animal food source, in addition to reducing the environmental pollution (8, 9). Different microorganism such as Actinomycetes, fungi and yeast strains as well as many types of bacteria can produce feather-hydrolyzing keratinase (10-14). These enzymes are important and numerously applied in different industries (15).

\section{Objectives}

The aim of this study was to investigate and evaluate the alkaline keratinase production by a nitrogen fixing, UVstable bacteriocin and IAA producer Bacillus sp. (16). Revealing the prospective multi-area application of $B$ pumilus, this research might lead to cell biomass production from the waste chicken feather.

\section{Materials and Methods}

\subsection{Microbiological Culture Media}

The composition of basal mineral medium, which has been used in this study, was [g/L]: Glucose [1], $\left(\mathrm{NH}_{4}\right)_{2} \mathrm{SO}_{4}$ [1], $\mathrm{KH}_{2} \mathrm{PO}_{4}$ [0.7], $\mathrm{K}_{2} \mathrm{HPO}_{4}[1.4]$ and $\mathrm{MgSO}_{4} .7 \mathrm{H}_{2} \mathrm{O}$ [0.1]. The $\mathrm{pH}$ was adjusted to 7.4, Medium was sterilized for $15 \mathrm{~min}$ utes at $121^{\circ} \mathrm{C}$ upon 15 lbs. L-tyrosine, Gelatin, Caseine powder and poultry feather were substituted with glucose when enzyme activities were being studied (17).

3.2. Screening, Isolation, Identification and Characterization of the Best Alkaline Protease Producing Bacillus sp.

Different nitrogen-fixing Bacillus isolates were obtained from the sea water of North of Iran and Persian Gulf, using heat-shock and incubation in an anaerobic jar, based on the method used by Shokri and Emtiazi (18). Identification of the isolates was initially carried out on the basis of their morphological, cultural, and biochemical characteristics using standard methods (19) and then confirmed using 16S rRNA. The related PCR reactions were performed using DNA extracts with universal primers RW01 (5'-AAC TGG AGG AAG GTG GGG AT-3') and DG74 (5'-AGG AGG TGA TCC AAC CGC A-3') obtained from CinnaGene Company (Tehran, Iran).

\subsection{Evaluation of Alkaline Protease}

Protease-producing Bacilli were enriched on feather with alkaline $\mathrm{pH}, 9,10$ and 11 and the $\mathrm{pH}$ of the culture media was optimized with $1 \mathrm{M} \mathrm{NaOH}$. The best alkaline protease producers were screened by measuring the released protein OD at $595 \mathrm{~nm}$. The alkaline protease activity evaluation was confirmed using alkaline skim milk, Gelatin and Casein agar culture media with pH 8, 9 and 10 (2).The maximum crude enzyme production was optimized at different $\mathrm{pH}$, salt and substrate levels.

\subsection{Assay of Alkaline Protease}

In all the experiments, alkaline protease assay was based on extra protein production from feather in different $\mathrm{pH}$ levels. As the supernatant enzyme, protease activity was assessed according to soluble protein production on feather, which was measured using Bradford reagent at $595 \mathrm{~nm}$. The calibration line of serum bovine was obtained for Bradford method (20).

\subsection{Crud Keratinase Freezing}

B. pumilus was grown on feather as the only source of carbon, nitrogen and energy for 3 days. The cells were separated with centrifugation at $6000 \mathrm{rpm}$ and the supernatant was condensed with freeze drying. The concentrated enzyme was assessed using $12 \%$ Acrylamid gel SDS-PAGE.

\subsection{SDS-PAGE and Zymogram of Protease}

To estimate the extracellular protein obtained from the keratin-grown cells, sodium dodecyl sulfate polyacrylamide gel electrophoresis (SDS-PAGE) was used. After electrophoresis, the gel, containing the protein standard ladder (low-molecular-mass range marker protein standards; Sigma, St. Louis, MO), was stained with Coomassie Brilliant Blue (CBB) R-250.

Zymography method has been proposed by Yamada et al. following Heussen and Dowdle. It is a method which can detect the protease activity in gel. This method was followed by 7.5\% mini-gel SDS-PAGE. After electrophoresis, the gels were divided in two parts. A part was washed in 2.5\% (v/v) Triton X-100 for 30 minutes to remove SDS and allow the renaturation of proteases. The gels were then incubated in phosphate buffer for 15 hours at $37^{\circ} \mathrm{C}$ and stained with Coomassie brilliant blue (CBB) R-250. Another part was transferred into $1 \%$ casein-solute and incubated for 35 minutes at $37^{\circ} \mathrm{C}$ in the presence of $50 \mathrm{mM}$ tris buffer with $\mathrm{pH}$ of 8.5. Following incubation, the gel was stained with Coomassie Brilliant Blue G-250 to visualize the hydrolysis zones (21). 
Talebi M et al.

\section{Results}

\subsection{Screening the Proteolytic Strain Among Nitrogen Fixing Bacteria}

Several nitrogen fixing bacilli were isolated by Zaghian et al. (16) these strains were enriched in different protein media to screen the best proteolytic Bacillus. The proteolytic activities of these strains were assayed using skim milk agar and casein agar. By this approach, presence of a clear zone was suggestive for proteases production from the test bacterial strains. The enriched strain on the feather was identified as B. pumilus with 99\% identity according to partial 16S rRNA gene sequence and it was given the strain designation of ZED17 (with accession No. JNO54254.1). This strain which was identified by biochemical and 165 rRNA with a high protease capability was selected for further studies.

The mentioned strain has high hydrolytic activities such as Gelatinase, Protease, Caseinase, Keratinase, Phosphatase and hemolyse activities which are shown in Figure 1. Even when this strain was only grown on feather, the multi-protease activity was determined in the supernatant.

Figure 1. Hydrolysis Activities of B. pumilus ZED17 in Different Substrate

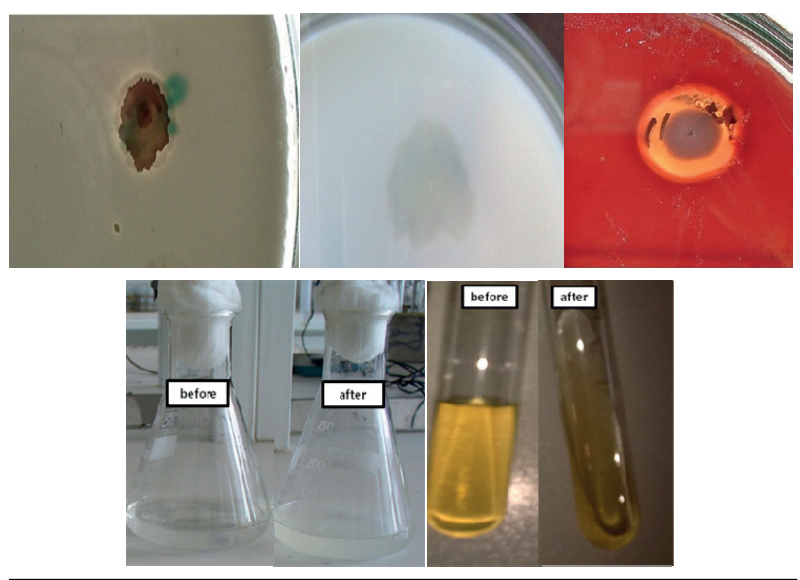

From left to right, Polyphosphate, Casein, Blood, Keratin and Gelatin media are used.

\subsection{Optimization of Keratinase Activity}

Enzyme formation is largely dependent on the condition of culture growth and composition of nutrient medium. Various carbon and nitrogen sources were used for production of protease by B. pumilus ZED17. The growth rate of this strain on keratin has been studied and the results are presented in Figure 2. As it is obvious, the maximum growth on $10 \mathrm{~g} / \mathrm{L}$ feather is occurred after 48 hours in which the maximum optical density was 0.6. However, adding another carbon or nitrogen source increases the maximum growth to 0.8 in $600 \mathrm{~nm}$.

The protein production rate of this Bacillus on keratin has been studied and the results are given in Figure 3. The maximum production of protein on $10 \mathrm{~g} / \mathrm{L}$ feather and 1 $\mathrm{g} / \mathrm{L}$ glucose as the carbon source occurred at the third day of incubation.

The protease production was higher when glucose was added to the keratin basal medium, in comparison with other sources (Figure 2). As shown in Figure 3, the maximum protease production occurs 72 hours after the incubation in the stationary phase. The effects of keratin concentration, addition of sugar, temperature, agitation and $\mathrm{NaCl}$ on protein production from chicken feather by this strain were investigated and the results are presented in Figure 4.

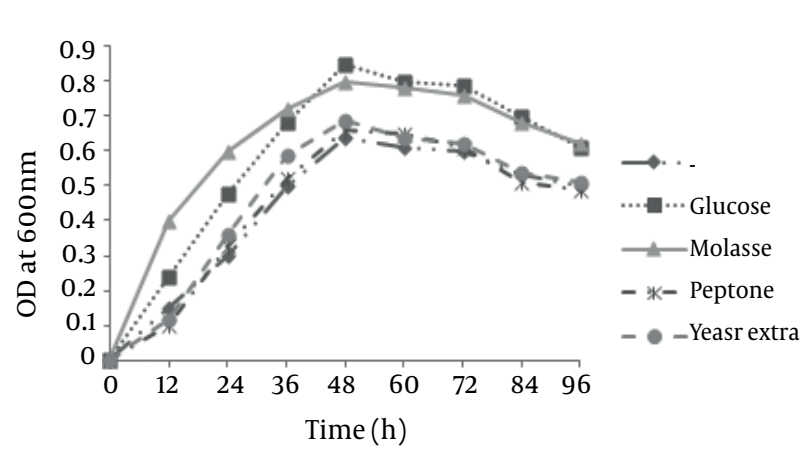

Figure 2. The Growth Rate of B. pumilus ZED17 on Chicken Feather $(10 \mathrm{~g} / \mathrm{L})$ After Addition of Other Carbon Sources in $\mathrm{pH}$ of 7 at $30^{\circ} \mathrm{C}$ and $120 \mathrm{rpm}$

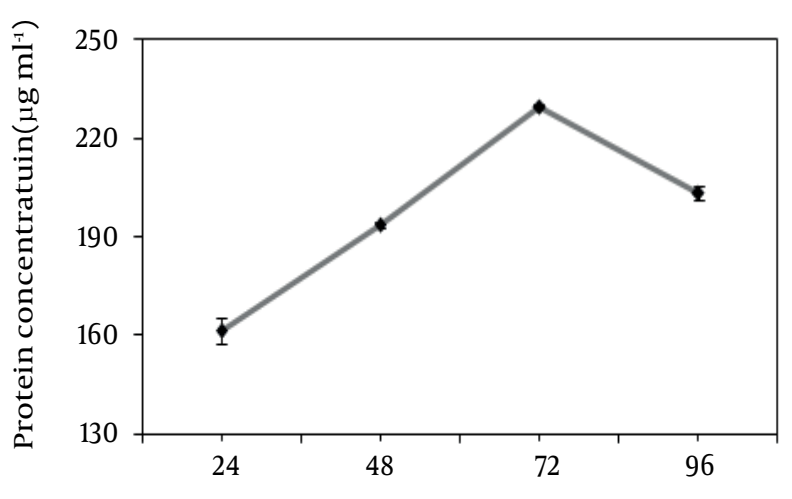

Figure 3. The Protein Production Rate of Bacillus on Chicken Feather (10 $\mathrm{g} / \mathrm{L}), \mathrm{pH}$ of 7 at $30^{\circ} \mathrm{C}$ and $120 \mathrm{rpm}$

Protease activity of Bacillus was stable under heat and acidic/basic treats and the optimum $\mathrm{pH}$ and temperature for keratinase production were 10 and $37^{\circ} \mathrm{C}$, respectively.

As shown in Figure 4, this enzyme is alkalophyle; so $40 \mathrm{~g} / \mathrm{L}$ of keratin as the only source of substrate at $\mathrm{pH}$ 10 has an increasing effect on protein production from feather. 
Talebi M et al.

Figure 4. Protein Production From Feather by B. pumilus in Different Conditions

A

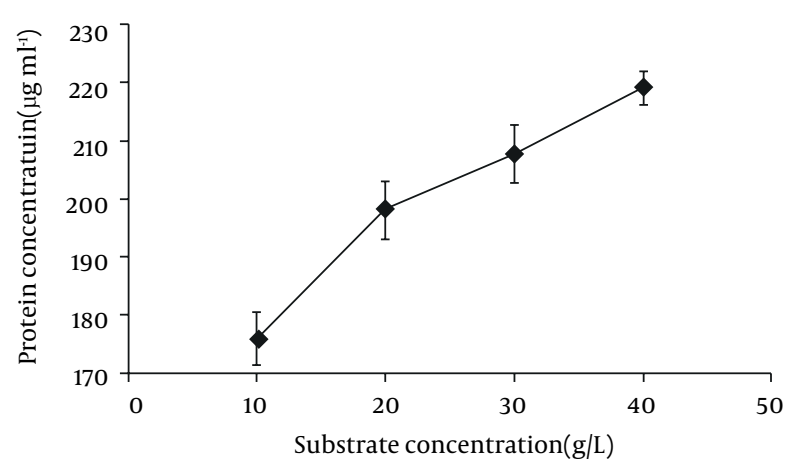

C

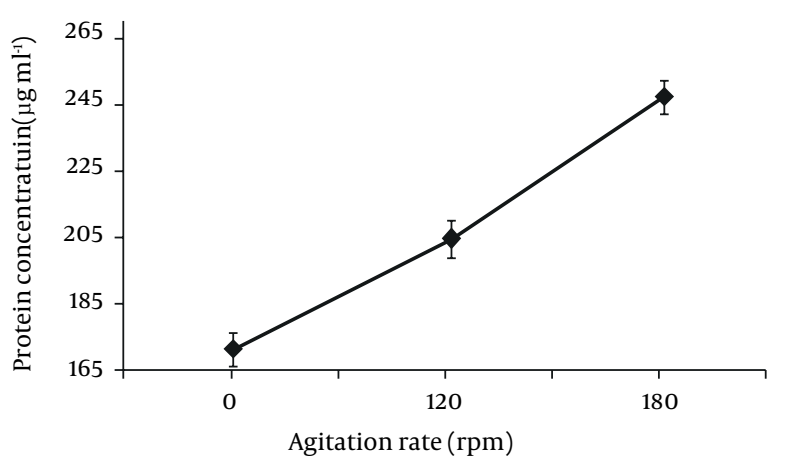

E
B

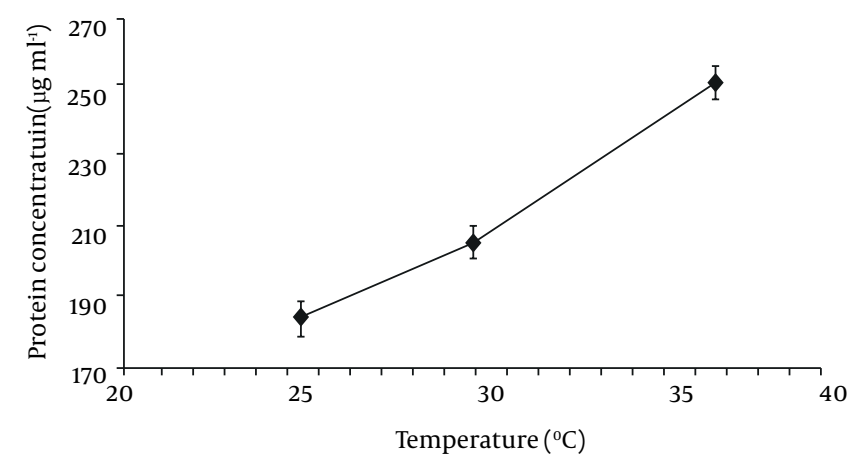

D

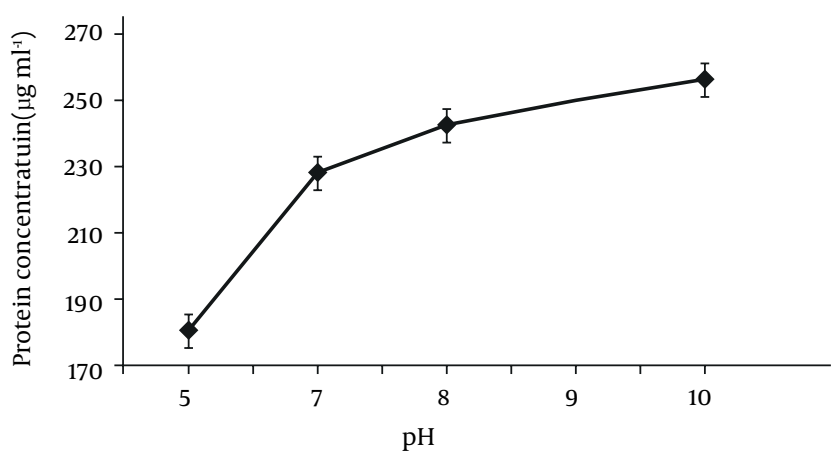

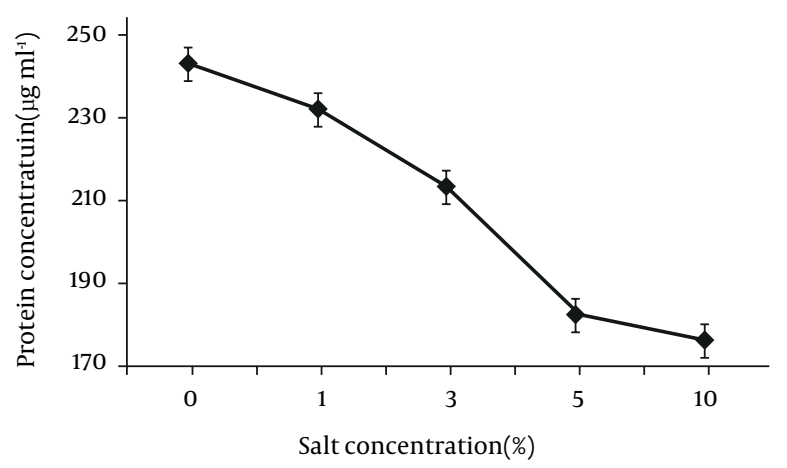

a, feather concentration $(\mathrm{g} / \mathrm{L}) ; \mathrm{b}$, temperature $\left({ }^{\circ} \mathrm{C}\right) ; \mathrm{c}$, agitation rate $(\mathrm{rpm}) ; \mathrm{d}, \mathrm{pH} ; \mathrm{e}, \mathrm{NaCl}$ concentration (\%)

\subsection{Enzyme Activities}

The supernatant of B. pumilus ZED17 that has been grown on feather was used for keratinase activity detection in different conditions. The results showed that a high activity of keratinase was obtained from B. pumilus ZED17 on feather meal which was assayed at $40^{\circ} \mathrm{C}$ in alkaline $\mathrm{pH}$ and $0.1 \mathrm{M} \mathrm{NaCl}$. The supernatant of keratingrown cells had protease activity which supported the high proteolysis activity of this isolate on keratin. 
Talebi M et al.

Figure 5. SDS Page and Zymogram of Concentrated Caseinase
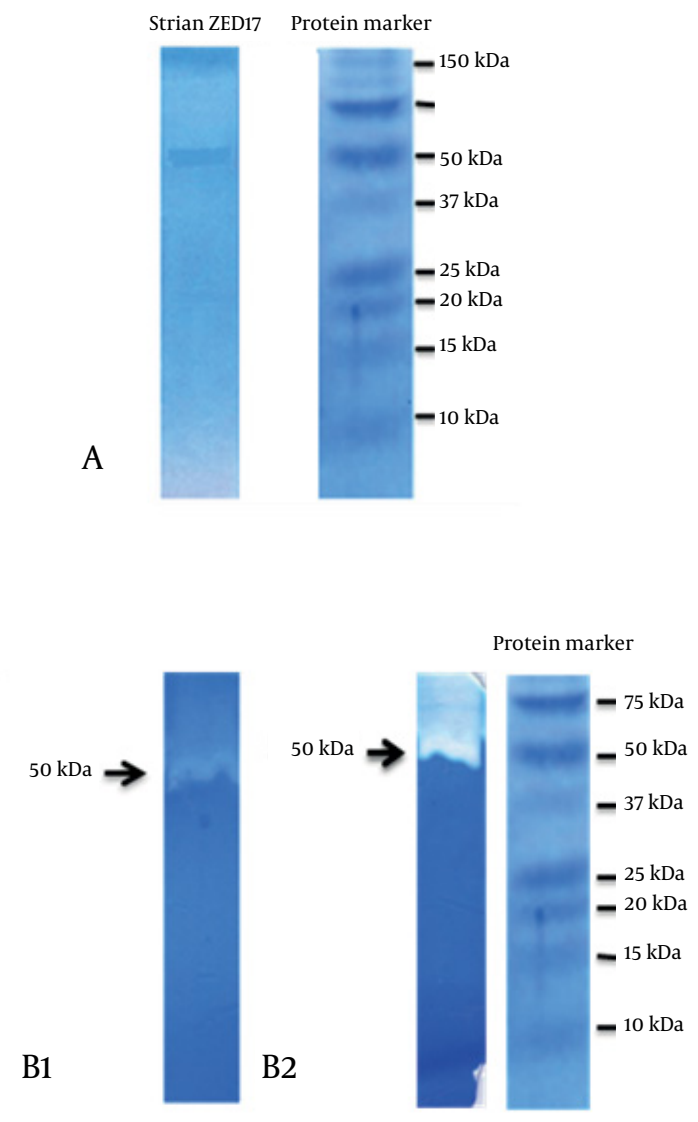

A, 12\% polyacrylamide gel showing only one band of concentrated enzyme on gel; b1, gel was incubated in phosphate buffer with Casein; b2, gel containing $1 \%$ Casein. The clear band in b1 and b2 show the 50 KDa Caseinase activities.

\subsection{SDS-PAGE and Gelatinase Page of B. pumilus ZED17}

The current concentrated enzyme was run for electrophoresis on $12 \%(\mathrm{w} / \mathrm{v})$ SDS-PAGE and a single band was observed. Using standard protein markers, size of the partially-purified enzyme on zymograph gel with clear area was found to be about $50 \mathrm{kDa}$ (Figure 5).

\section{Discussion}

B. pumilus ZED17 has different activities such as Gelatinase, Protease, Caseinase, Keratinase, Phosphatase and Cytolysis. Maximum production of protein on $10 \mathrm{~g} / \mathrm{L}$ feather and $1 \mathrm{~g} / \mathrm{L}$ glucose, as the carbon source, occurred at the third days of incubation. The optimum $\mathrm{pH}$ and temperature for enzyme production were 10 and $37^{\circ} \mathrm{C}$, respectively. The results showed a higher activity of keratinase obtained from B. pumilus ZED17 on feather meal, which was assayed at $40^{\circ} \mathrm{C}$ in alkaline $\mathrm{pH}$ and $0.1 \mathrm{M} \mathrm{NaCl}$.

Protease activities of Bacillus vary with $\mathrm{pH}$ alternation, which have been reported by Guangrong and others (2224). Among the proteases, alkaline proteases are the most important ones in the industry and usually, maximum production occurs in the stationery or post exponential phase of their growth. The compositions of medium, carbon sources and other factors are important for protease production in Bacillus. Morya et al. $(24,25)$ reported that optimum temperature for Bacillus sp. Protease action is in the range of $30-70^{\circ} \mathrm{C}$, while, Ammar et al. (26) obtained $55^{\circ} \mathrm{C}$ as the optimum temperature. Some other researcher have come up with rather similar results, e. g. $60^{\circ} \mathrm{C}$ at $\mathrm{pH}$ of 8 for B. firmus and $60^{\circ} \mathrm{C}$ at $\mathrm{pH} 9$ for Bacillus strain $\operatorname{SAL1}(27,28)$.

A variety of molecular weights for proteases produced by other Bacillus species has been reported: 49 kDa Bacillus sp. HUTBS71 (29), 75 KDa Bacillus sp. S17110 (30), 30.9 kDa Bacillus sp. HS08A (24) and 75.0 kDa Bacillus sp. S17110 (31). Bacillus strain SAL1 has shown alkalin protease band with the molecular weight of $27 \mathrm{kDa}$ in the SDS-page (32). Fakhfakh-Zouari (31) isolated and characterized a keratinolytic enzyme from a newly isolated B. pumilus strain A1 on chicken feather meal with molecular mass of 34000 Da. They also found that the optimum condition for keratinase production on keratin was in $\mathrm{pH} 9.0$ at $60^{\circ} \mathrm{C}$. Novel Keratinase from B. subtilis S14, exhibiting remarkable dehairing capabilities, has been used as an alternative for sodium sulfide (17). Mazotto et al. described that B. subtilis 1273 uses feather as a substrate for keratinase production (32). A 45-kDa keratinase obtained from B. pumilus KS12 was reported by Rajput et al. (33).

In the present study, , size of the concentrated enzyme was found to be about $50 \mathrm{kDa}$ using standard protein marker and due to its multi-activity on different substrates such as Casein, Gelatin and keratin, it was introduced as a multi-enzyme. The zymogram test showed hydrolysis activities of casein around the $50-\mathrm{kD}$ band.

\section{Acknowledgements}

The authors would like to thank Dr. Gholamreza Balali, Department of Biology, University of Isfahan for his collaboration.

\section{Authors' Contribution}

Marzieh Talebi did Acquisition of data, Analysis and interpretation of data, Statistical analysis and material support. Giti Emtiazi Developed the original idea and the protocol, Study supervision and technical support, Drafting of the manuscript. Abbas Akhavan Sepahy study supervision, Administrative support. Saeideh Zaghian helped in Material support, Drafting of the manuscript.

\section{Financial Disclosure}

Upon completion of the study, all authors had no conflict of interest. 


\section{Funding/Support}

This research was supported partially by Tehran Science and Research branch of Islamic Azad University.

\section{References}

1. Bergey DH, Boone DR. Bergye's manual of systematic bacteriology. 3 ed:Springer Verlag; 2009.

2. Emtiazi G, Nahvi I, Maal KB. Production and immobilization of alkaline protease byBacillus polymyxawhich degrades various proteins. Int J Environ Stud. 2005;62(1):101-107.

3. Maal KB, Emtiazi G, Nahvi I. Production of alkaline protease by Bacillus cereus and Bacillus polymixa in new industrial culture medium and its immobilization. Afr J Microbiol Res. 2009;3(9):491-497.

4. Ram MS, Singh L, Alam SI, Aggarwal MK. Extracellular protease from Bacillus coagulans, a psychrotrophic, Antarctic bacterium. World J Microbiol Biotechnol. 1994;10(3):356-357.

5. Zambare VP, Nilegaonkar SS, Kanekar PP. Production of an alkaline protease by Bacillus cereus MCM B-326 and its application as a dehairing agent. World J Microbiol Biotechnol. 2007;23(11):15691574.

6. Prakasham RS, Rao Ch S, Sarma PN. Green gram husk-an inexpensive substrate for alkaline protease production by Bacillus sp. in solid-state fermentation. Bioresour Technol. 2006;97(13):1449-54.

7. Brandelli A. Bacterial Keratinases: Useful Enzymes for Bioprocessing Agroindustrial Wastes and Beyond. Food Bioprocess Tech. 2007;1(2):105-116.

8. Shih JCH. Recent Development in Poultry Waste Dizgestion and Feather Utilization-A Review. Poultry Sci.1993;72(9):1617-1620.

9. Papadopoulos MC, El Boushy AR, Roodbeen AE, Ketelaars EH. Effects of processing time and moisture content on amino acid composition and nitrogen characteristics of feather meal. Anim Feed Sci Tech. 1986;14(3-4):279-290.

10. Park GT, Son HJ. Keratinolytic activity of Bacillus megaterium F7-1, a feather-degrading mesophilic bacterium. Microbiol Res. 2009;164(4):478-85.

11. Kaul S, Sumbali G. Keratinolysis by poultry farm soil fungi. Mycopathologia.1997;139(3):137-40.

12. Riffel A, Brandelli A. Keratinolytic bacteria isolated from feather waste. Braz J Microbiol. 2006;37(3):395-399.

13. Duarte TR, Oliveira SS, Macrae A, Cedrola SML, Mazotto AM Souza EP, et al. Increased expression of keratinase and other peptidases by Candida parapsilosis mutants. Braz J Med Biol Res. 2011;44(3):212-216.

14. Li J, Shi PJ, Han XY, Meng K, Yang PL, Wang YR, et al. Functional expression of the keratinolytic serine protease gene sfp2 from Streptomyces fradiae var. k11 in Pichia pastoris. Protein Expr Purif. 2007;54(1):79-86.

15. Matoba S, Morano KA, Klionsky DJ, Kim K, Ogrydziak DM. Dipeptidyl aminopeptidase processing and biosynthesis of alkaline extracellular protease from Yarrowia lipolytica. Microbiology. 1997;143 ( Pt 10):3263-72.

16. Zaghian S, Shokri D, Emtiazi G. Co-production of a UV-stable bacteriocin-like inhibitory substance (BLIS) and indole-3-acetic acid hormone (IAA) and their optimization by Taguchi design in Bacillus pumilus. Annals Microbiol. 2011;62(3):1189-1197.
17. Macedo AJ, da Silva WO, Gava R, Driemeier D, Henriques JA, Termignoni C. Novel keratinase from Bacillus subtilis S14 exhibiting remarkable dehairing capabilities. Appl Environ Microbiol. 2005;71(1):594-6.

18. Shokri D, Emtiazi G. Indole-3-acetic acid (IAA) production in symbiotic and non-symbiotic nitrogen-fixing bacteria and its optimization by Taguchi design. Curr Microbiol. 2010;61(3):217-25.

19. Garrity GM, Bell JA, Lilburn TG. Taxonomic outline of the prokaryotes. Bergey's manual of systematic bacteriology. New York Berlin Heidelberg: Springer; 2004.

20. Bradford MM. A rapid and sensitive method for the quantitation of microgram quantities of protein utilizing the principle of protein-dye binding. Anal Biochem. 1976;72(1-2):248-254

21. Ghafoor A, Hasnain S. Purification and characterization of an extracellular protease from Bacillus subtilis EAG-2 strain isolated from ornamental plant nursery. Pol J Microbiol. 2010;59(2):107-12.

22. Schaeffer P. Sporulation and the production of antibiotics, exoenzymes, and exotonins. Bacteriol Rev.1969;33(1):48-71.

23. Sharipova MR, Shakirov EV, Gabdrakhmanova LA, Balaban NP, Kalacheva NV, Rudenskaya GN, et al. Factors influencing the cellular location of proteolytic enzymes of Bacillus intermedius. Med Sci Monit. 2000;6(1):8-12.

24. Guangrong H, Tiejing Y, Po H, Jiaxing J. Purification and characterization of a protease from thermophilic Bacillus strain HSO8. Afr J Biotechnol. 2010;5(24):2433-2438.

25. Morya V, Yadav D. Production and partial characterization of neutral protease by an indigenously isolated strain of Aspergillus tubingensis NIICC-0 8155. Internet J Microbiol. 2010;8(1).

26. Ammar MS, Bayoumi RA, El-Kasaby AMH, Soliman AQM. Purification and properties of thermostable protease by Bacillus brevis geltinoamylolyticus using fish wastes (Fi W) and poultry waste (Po W) under solid state fermentation (SSF) conditions. Sic Conf Al-Azhar Univ Fac Sci 2003;5:25-27.

27. Almas S, Hameed A, Shelly D, Mohan P. Purification and characterization of a novel protease from Bacillus strain SAL1. Afr J Biotechnol. 2009;8(15):3603-3609.

28. Joshi BH. Purification and characterization of a novel protease from Bacillus firmus Tap5 isolated from tannery waste. J Appl Sci Res. 2010;6(8):1068-1076.

29. Akel H, Al-Quadan F, Yousef TK. Characterization of a purified thermostable protease from hyperthermophilic Bacillus strain HUTBS71. EurJ Sci Res. 2009;31:280-288.

30. Jung SC, Paik HR, Kim MS, Baik KS, Lee WY, Seong CN, et al. InhAlike protease secreted by Bacillus sp. S17110 inhabited in turban shell.J Microbiol. 2007;45(5):402-8.

31. Fakhfakh-Zouari N, Hmidet N, Haddar A, Kanoun S, Nasri M A novel serine metallokeratinase from a newly isolated Bacillus pumilus A1 grown on chicken feather meal: biochemical and molecular characterization. Appl Biochem Biotechnol. 2010;162(2):329-44.

32. Mazotto AM, Coelho RR, Cedrola SM, de Lima MF, Couri S, Paraguai de Souza E, et al. Keratinase Production by Three Bacillus spp. Using Feather Meal and Whole Feather as Substrate in a Submerged Fermentation. Enzyme Res. 2011;2011:523780.

33. Rajput R, Sharma R, Gupta R. Cloning and characterization of a thermostable detergent-compatible recombinant keratinase from Bacillus pumilus KS12. Biotechnol Appl Biochem. 2011;58(2):109-118. 